\title{
TEKNIK PENGUMPULAN DATA PADA AUDIT SISTEM INFORMASI DENGAN FRAMEWORK COBIT
}

\author{
Putu Dhanu Driya1, *, I Gusti Lanang Agung Raditra Putra 2, I Made Ardwi \\ Pradnyana $^{3}$ \\ 1,2.3 Prodi Sistem Informasi Jurusan Teknik Informatika Fakultas Teknik dan Kejuruan Universitas Pendidikan \\ Ganesha, Jln. Udayana No. 11 Singaraja 81117 INDONESIA
}

\section{Abstrak}

Perkembangan zaman telah mendorong organisasi untuk memanfaatkan SI/TI dalam mendukung bisnis organisasi. Selarasnya antara SI/TI organisasi dan tujuan organisasi maka proses pencapaian tujuan pun akan semakin cepat. Pebelitian ini bertujuan memberikan pemahaman terkait teknik pengumpulan data pada audit sistem informasi dengan framework COBIT dan aspek-aspek pertimbangan dalam memilih teknik pengumpulan data pada audit sistem informasi dengan framework COBIT. Penelitian ini menggunakan studi literatur sebagai sumber data primer dengan teknik matriks sintetis untuk menarik kesimpulan dari sumber literatur. Pengumpulan data merupakan aspek fundamental dalam pelaksanaan audit sistem informasi, kualitas data yang didapatkan akan mempengaruhi tingkat akurasi audit sistem informasi yang dilaksanakan. Penentuan teknik pengambilan data dapat mengacu pada tahapan pertama audit yakni penentuan ruang lingkup audit, hal ini sangat penting mengingat pengumpulan data akan mempengaruhi seluruh tahap lanjutan dari audit sistem informasi, termasuk mempengaruhi hasil audit.
\end{abstract}

Kata Kunci:

Audit, Sistem Informasi,

Cobit, Pengumpulan

Data

\begin{abstract}
Nowadays, organizations need to utilize IS/IT in supporting business organizations. In harmony between IS/IT organization and organizational goals, the process of achieving goals will be faster. This research aims to provide an understanding of data collection techniques on information system audits with the COBIT framework and aspects of consideration in choosing data collection on information systems audits with the COBIT framework. This research uses literature study as the primary data source with synthetic matrix technique to draw conclusions from literature sources. Data collection is a fundamental aspect in the implementation of an information system audit, the quality of the data obtained will affect the level of accuracy of the information system audit carried out. Data collection techniques can refer to the first stage of the audit, namely determining the scope of the audit, this is very important considering that data collection will affect all further stages of the information system audit, including influencing the audit results.
\end{abstract}

Keywords:

Audit, Information

System, COBIT, Data Gathering

\section{PENDAHULUAN}

Perkembangan zaman saat ini telah mendorong organisasi untuk memanfaatkan teknologi informasi dalam menjalankan kegiatan proses bisnis organisasinya. Keberadaan teknologi informasi mampu mendukung organisasi dalam memberikan informasi yang akurat, relevan, dan cepat. Dengan selarasnya tujuan organisasi dan Sistem Informasi/Teknologi Informasi organisasi, dapat mempercepat proses pencapaian tujuan organisasi tersebut, namun tentu diperlukan adanya pengawasan dan pemeliharaan agar SI/TI organisasi berjalan dengan baik (Andry \& Setiawan, 2019). Masalah yang kerap terjadi dalam SI/TI organisasi diantaranya sistem yang tidak efisien akibat menggunakan sumberdaya yang berlebih (overload), efektifitas sistem yang kurang optimal, dan terjadinya perubahan standar operasional prosedur organisasi. Sebuah sistem informasi akan dikatakan baik dan layak apabila sudah memenuhi standar dan 
adanya suatu tata kelola TI yang baik serta mengacu pada keefektifan penggunaan sistem tersebut yang dinilai berdasarkan kepuasan pengguna sistem (Andry \& Setiawan, 2019). Audit pada dasarnya merupakan kegiatan mengevaluasi serta pengumpulan bukti-bukti mengenai data atau informasi dengan tujuan untuk memastikan dan memberikan tingkat kesesuaian antara informasi yang didapatkan dengan standar yang telah ditetapkan (Amalia et al., 2020). Menurut (Arens et al., 2017): "Auditing is the accumulation and evaluation of evidence aboutinformation todetermine and report on the degree of correspondence between the information and established criteria. Auditing should bedone by a competent, independent person", sehingga dapat dikatakan bahwa audit merupakan akumulasi dan evaluasi bukti tentang informasi untuk menentukan laporan tingkat kesesuaian antara informasi dan kriteria yang sudah ditetapkan, dan kegiatan ini harus dilakukan oleh orang yang independen dan kompeten agar proses audit dapat dilakukan dengan optimal tanpa pengaruh dari pihak manapun.

Seiring dengan peranan TI bagi organisasi yang meningkat maka muncul sebuah jenis audit baru, yakni audit sistem informasi. Audit sistem informasi merupakan salah satu bentuk audit operasional, sebagai salah satu audit operasional, maka aspek evaluasinya adalah efektivitas, efisiensi, dan tingkat ekonomis tidaknya unit fungsional sistem informasi pada organisasi terjadap manajemen sumber daya informasi (Sukmajaya \& Johanes Fernandes Andry, 2017). Audit Sistem Informasi juga bertujuan mengevaluasi kesesuaian antara rancangan sistem informasi dan efektifitas, efisiensi, dan tingkat keekonomisan penggunaannya, termasuk juga dalam hal mekanisme keamanan sistem yang memadai, serta integrasi sistem (Setya \& Wella, 2018).

Pelaksanaan suatu audit sistem informasi dapat dilakukan dengan dukungan adanya kerangka kerja atau framework yang menjadi panduan sistematis dalam pelaksanaan proses audit. Framework yang digunakan diantaranya adalah COBIT 2019, COBIT 5.0, COBIT 4.1, ITIL, COSO, CICA, ISO, BSBS, FIPS, TOGAF, dan sejenisnya. COBIT merupakan singkatan dari Control Objective for Information and related Technology merupakan framework yang terdiri dari domain dan proses yang digunakan untuk mengatur aktivitas dan logical structure (Yaniar et al., 2020). COBIT memiliki prinsip dalam menyediakan informasi yang diperlukan untuk mencapai tujuan organisasi (Nainggolan, 2021).

Pengumpulan data merupakan aspek fundamental dalam pelaksanaan audit sistem informasi, kualitas data yang didapatkan akan mempengaruhi tingkat akurasi audit sistem informasi yang dilaksanakan, oleh karena itu pemilihan teknik pengumpulan data yang tepat, akan menjadi salah satu pertimbangan agar dapat menghasilkan hasil audit yang akurat. Kesalahan dalam penggunaan metode pengumpulan data akan dapat hasil audit yang kurang relevan dan kurang akurat dengan kondisi organisasi yang diaudit. Dalam penelusuran sebanyak 25 jurnal, penulis menemukan bahwa teknik yang biasa dilakukan diantaranya wawancara, kuesioner, observasi, dan studi dokumen. Teknik yang digunakan selama proses audit dapat digunakan secara sendiri-sendiri dan juga kombinasi antara dua metode atau lebih.

Berdasarkan hasil review awal dari beberapa artikel, ditemukan hasil penelitian dari (Yaniar et al., 2020) dengan judul "IS Governance Evaluation Using COBIT 5 Framework on the Central Statistics Agency of Banyumas District" menggunakan teknik pengumpulan data kombinasi antara kuesioner dan wawancara serta observasi, namun penelitian yang dilakukan oleh (Amalia et al., 2020) yang berjudul "Audit Sistem Informasi pada Perpustakaan ARS University Menggunakan Framework COBIT 5" menggunakan teknik kombinasi antara observasi dan kuesioner, hal ini sama dengan penelitian dari (Setya \& Wella, 2018) yang berjudul "COBIT 5.0: Capability Level of Information Technology Directorate General of Treasury" yang juga menggunakan kombinasi obervasi, wawancara, dan kuesioner, begitupula dengan penelitian dari (Sukmajaya \& Johanes Fernandes Andry, 2017) dengan "Audit Sistem Informasi Pada Aplikasi Accurate Menggunakan Model COBIT Framework 4.1 (Studi Kasus" PT. Setia Jaya Teknologi) yang menggunakan kombinasi wawancara dan kuesioner. Penelitian dari (Andry \& Hartono, 2017) yang berjudul "Performance Measurement of IT Based on COBIT Assessment: A Case Study" hanya mengunakan teknik kuesioner saja. Berbeda lagi dengan penelitian dari (Oktaviana et al., 2019) yang berjudul "Evaluasi IT Governance Dengan Framework COBIT 5.0 (Studi Kasus: PT. XYZ)" yang menggunakan kombinasi studi pustaka, wawancara, observasi, serta dokumentasi, kemudian penelitian dari (Bayastura et al., 2021) yang berjudul "Analisis dan Perancangan Tata Kelola Teknologi Informasi Menggunakan Framework COBIT 2019 Pada PT. XYZ” yang hanya menggunakan metode wawancara.

Penelitian ini bertujuan untuk melakukan review artikel terkait teknik pengumpulan data pada audit sistem informasi dengan framework COBIT dan memberikan pemahaman terkait aspek-aspek pertimbangan dalam memilih teknik pengumpulan data pada audit sistem informasi dengan framework COBIT. 


\section{METODE}

Pada penelitian ini menggunakan metode riset pustaka, dengan menggunakan jenis data sekunder. Metode yang akan digunakan untuk pengkajian ini adalah studi literatur. Data yang telah diperoleh kemudian dikompulasi, dianalisis, dan disimpulkan sehingga mendapatkan kesimpulan mengenai studi literatur. Penelitian kepustakaan dapat dikatakan sebagai kegiatan penelitian dimana pengumpulan data dan informasi didapatkan dengan bantuan material perpustakaan seperti buku referensi, jurnal, artikel, prosiding yang berkaitan dengan topik penelitian (Sari \& Asmendri, 2018). Metode studi literatur merupakan serangkaian kegiatan mengenai pengumpulan data Pustaka, membaca, mencatat, serta mengolah bahan penelitian (S. R. Rahayu, 2018). Riset kepustakaan merupakan kegiatan penelusuran Pustaka sebagai bahan utama penelitian tanpa memerlukan riset lapangan (Sari \& Asmendri, 2018). Dalam penelitian studi Pustaka ada empat ciri utama yang harus diperhatikan peneliti: 1) Peneliti harus berhadapan langsung dengan teks atau data angka, bukan dengan pengetahuan langsung dari lapangan. 2) Data Pustaka bersumber dari penelitian lain yang kredibel dan berkualitas. 3) Data pustaka umumnya adalah data sekunder, sehingga data didapatkan dari tangan kedua, tidak data orisinil. 3) Kondisi data Pustaka tidak dibatasi oleh ruang dan waktu (Supriyadi, 2017). Menurut (Sari \& Asmendri, 2018), Langkah dalam penelitian studi kepustakaan diantaranya: 1) Mencari informasi yang mendukung topik. 2) Membaca dan membuat catatan penelitian terkait. 3) Mengulas bahan bacaan. 4) Menyajikan hasil analisis kepustakaan. Menurut (Mirzaqon \& Purwoko, 2017), tahapan dalam penelitian kepustakaan diuraikan sebagai berikut: 1) Pemilihan topik. 2) Eksplorasi informasi. 3) Menentukan fokus penelitian. 4) Pengumpulan sumber data. 5) Persiapan penyajian data. 6) Penyusunan laporan.

Berdasarkan pernyataan tersebut, metode kepustakaan melibatkan 3 komponen kunci, yang diilustrasikan pada gambar berikut.

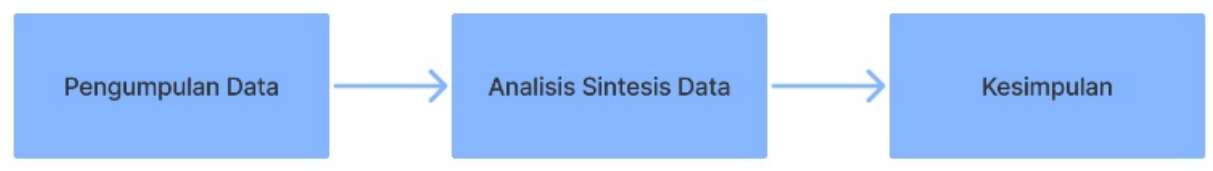

Gambar 1. Tahapan kunci riset pustaka

Pengumpulan sumber informasi yang berkualitas yang didapatkan dari artikel jurnal, membaca dan mengulas informasi yang didapatkan dari jurnal dengan merujuk pada bagian teknik audit sistem informasi dengan menggunakan teknik sintesis, teknik sintesis merupakan proses mengintegrasikan hasil analisis sumber informasi berdasarkan persamaan dan perbedaan sumber dan membuat kesimpulan berdasarkan kedua hal tersebut. Pada teknik sintesis ini digunakan matriks sintesis, dengan cara: 1) Identifikasi minimal 15 artikel yang sangat relevan degan fokus penelitian dalam hal ini adalah audit system informasi dengan framework COBIT. 2) Membuat kolom untuk mengidentifikasi beberapa hal yakni: tujuan penelitian, metode pengumpulan data yang digunakan, perbedaan dan persamaan masing-masing artikel, langkah terakhir adalah menyajikan hasil ulasan (Ulhaq \& Rahmayanti, 2020).

\section{HASIL DAN PEMBAHASAN}

\section{A. COBIT ISACA}

COBIT merupakan singkatan dari Control Objectives for Information and Related Technology, merupakan kerangka kerja tata Kelola TI yang dapat membantu auditor, menjembatani resiko bisnis, dan menangani masalah Teknik sistem informasi (Nainggolan, 2021). COBIT merupakan framework umum yang dapat digunakan untuk hampir semua organisasi, baik organisasi profit maupun non-profit (Amalia et al., 2020). Menurut Buku COBIT Student Book, COBIT memiliki empat domain yang dijabarkan sebagai berikut: 1) Plan and Organize (PO) mencakup pembahasan strategi, taktik, dan identifikasi teknologi informasi agar mampu mencapai tujuan bisnis organisasi. 2) Acquire and Implement (AI) mencakup pengembangan solusi teknologi informasi yang akan diidentifikasi, dikembangkan, dan diimplementasikan yang mana selanjutnya akan diintegrasikan ke seluruh proses bisnis organisasi. 3) Deliver and Support, merupakan domain yang berfokus pada aspek penyampaian teknologi informasi terhadap dukungan dan layanan teknologi informasi pada proses bisnis organisasi (penanganan keamanan TI hingga manajemen data pengguna). 4) Monitor and Evaluate (ME), domain ini menekankan pentingnya semua proses teknologi informasi harus diakses secara berkala demi menjaga kualitas dan kesesuaian antara implementasi teknologi informasi saat ini dengan standar yang telah ditetapkan (IT Governance Institute, 2004). Pada 
domain plan and organize terdapat kriteria penilaian dan pengukuran yang mencakup Key Goal Indicators, Critical Success Factors, Key Performance Indicators, serta Maturity Model.

Pada Buku COBIT Student Book dinyatakan bahwa COBIT memiliki komponen yang meliputi: 1) Framework yang bertujuan memberikan panduan dan mengatur tata Kelola TI dan menghubungkan kebutuhan bisnis organisasi. 2) Process Descriptions yang merupakan sebuah model referensi untuk organisasi dalam hal perencanaan, mengembangkan, mengjalankan, dan memantau. 3) Control Objectives untuk menyediakan panduan persyaratan untuk manajemen organisasi dalam mencapai kontrol TI yang efektif di setiap proses bisnis organisasi. 4) Management Guidelines merupakan pedoman manajemen untuk menetapkan tanggung jawab, pengukuran kinerja, dan keterkaitan antara setiap proses yang ada. 5) Maturity Models, merupakan aspek penilaian kematangan pada setiap proses mengenai kondisi saat ini dengan kondisi yang sudah ditetapkan standar, sehingga bertujuan mengukur kesenjangan implementasi TI saat ini di organisasi.

COBIT bertujuan untuk memudahkan auditor dalam memberikan rekomendasi perbaikan bagi organisasi dalam hal peningkatan manajemen sistem informasi dimasa mendatang (Yaniar et al., 2020). Proses pelaksanaan audit sistem informasi dibagi menjadi empat tahapan, yakni: Planning, Preparation, Implementation, dan Reporting. Pada fase implementation dilakukan evaluasi dari data yang didapatkan melalui berbagai metode pengumpulan data, seperti wawancara, observasi, dan survei (Setya \& Wella, 2018).

\section{B. Hasil Matriks Sintetis Literatur Review}

Tabel 1. Tabel matriks sintetis

\begin{tabular}{|c|c|c|c|c|c|}
\hline No. & $\begin{array}{c}\text { Judul } \\
\text { Penelitian } \\
\text { dan Peneliti }\end{array}$ & $\begin{array}{c}\text { Tujuan } \\
\text { Peneltian }\end{array}$ & $\begin{array}{c}\text { Teknik } \\
\text { Pengumpulan Data }\end{array}$ & Hasil Penelitian & Publikasi \\
\hline 1 & $\begin{array}{l}\text { Performance } \\
\text { Measurement } \\
\text { of IT Based on } \\
\text { COBIT } \\
\text { Assessment: A } \\
\text { Case Study } \\
\text { (Andry \& } \\
\text { Hartono, } \\
\text { 2017). }\end{array}$ & $\begin{array}{l}\text { Mendapatkan } \\
\text { gambaran tata } \\
\text { Kelola } \\
\text { teknologi } \\
\text { informasi dan } \\
\text { kematangan } \\
\text { dalam } \\
\text { perusahaan }\end{array}$ & $\begin{array}{l}\text { Kuesioner pada } 40 \\
\text { responden ( } 5 \text { dari } \\
\text { top manajemen dan } \\
35 \text { dari masing- } \\
\text { masing } \\
\text { departemen) }\end{array}$ & $\begin{array}{l}\text { Tingkat } \\
\text { kematangan tata } \\
\text { Kelola TI dalam } \\
\text { domain PO berada } \\
\text { di nilai } 1,9 \text { (initial) } \\
\text { hingga } \\
\text { (defined) }\end{array}$ & $\begin{array}{lr}\text { Jurnal Sistem } \\
\text { Informasi } \\
\text { Indonesia (JSII) } \\
\text { Volume r, } \\
\text { Nomor } 1, \\
\text { Tahun 2019 - } \\
\text { AISINDO. }\end{array}$ \\
\hline 2 & $\begin{array}{l}\text { IS Governance } \\
\text { Evaluation } \\
\text { Using COBIT } 5 \\
\text { Framework } \\
\text { on the Central } \\
\text { Statistics } \\
\text { Agency of } \\
\text { Banyumas } \\
\text { District } \\
\text { (Yaniar et al., } \\
\text { 2020). }\end{array}$ & $\begin{array}{l}\text { Mengetahui } \\
\text { tingkat } \\
\text { kapabilitas } \\
\text { Kantor Badan } \\
\text { Pusat Statistik } \\
\text { Kabupaten } \\
\text { Banyumas }\end{array}$ & 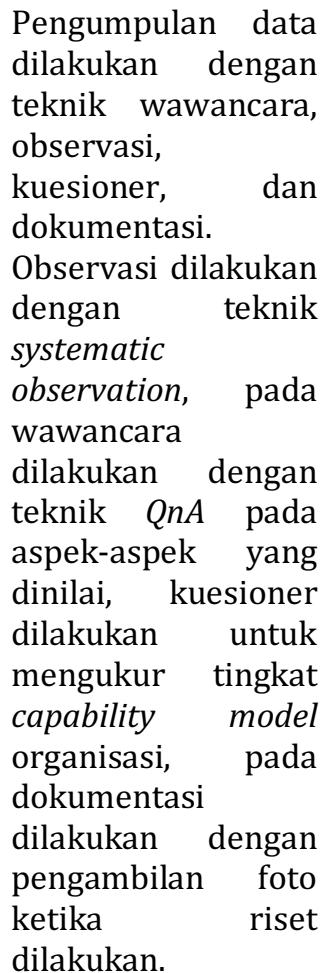 & $\begin{array}{l}\text { Tingkat kapabilitas } \\
\text { BPS saat ini berada } \\
\text { di level } 3 \text { yakni } \\
\text { established process, } \\
\text { sehingga sudah } \\
\text { berjalan dengan } \\
\text { baik dan sudah } \\
\text { mencapai tujuan } \\
\text { bisnis organisasi. }\end{array}$ & $\begin{array}{l}\text { Journal of } \\
\text { Computer } \\
\text { Science and } \\
\text { Engineering, } \\
\text { Volume 1, } \\
\text { Nomor 1, 2020. }\end{array}$ \\
\hline
\end{tabular}




\begin{tabular}{|c|c|c|c|c|c|}
\hline No. & $\begin{array}{c}\text { Judul } \\
\text { Penelitian } \\
\text { dan Peneliti }\end{array}$ & $\begin{array}{c}\text { Tujuan } \\
\text { Peneltian }\end{array}$ & $\begin{array}{c}\text { Teknik } \\
\text { Pengumpulan Data }\end{array}$ & Hasil Penelitian & Publikasi \\
\hline 3 & $\begin{array}{l}\text { Audit Sistem } \\
\text { Informasi } \\
\text { pada ARS } \\
\text { Perpustakaa } \\
\text { n University } \\
\text { Menggunaka } \\
\text { n Framework } \\
\text { COBIT 5 } \\
\text { (Amalia et al., } \\
\text { 2020). }\end{array}$ & $\begin{array}{l}\text { Melakukan } \\
\text { evaluasi tingkat } \\
\text { penerapan } \\
\text { manajemen } \\
\text { operasional, } \\
\text { keuangan, } \\
\text { masalah, dan } \\
\text { data yang ada } \\
\text { di perpustakaa, }\end{array}$ & 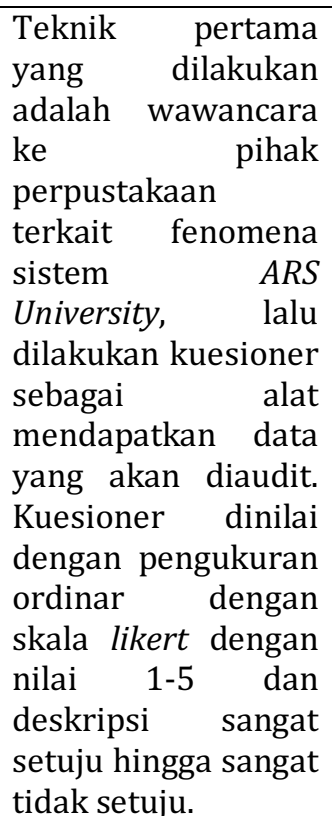 & $\begin{array}{lr}\text { ARS } & \text { University } \\
\text { memiliki } & \text { nilai } \\
\text { maturity } & \text { level di } \\
\text { tingkat } 4 . & \end{array}$ & $\begin{array}{l}\text { Jurnal Sains } \\
\text { dan } \\
\text { Informatika, } \\
\text { Volume 6, } \\
\text { Nomor 2, 2020. }\end{array}$ \\
\hline 4 & $\begin{array}{l}\text { COBIT 5.0: } \\
\text { Capability } \\
\text { Level of } \\
\text { Information } \\
\text { Technology } \\
\text { Directorate } \\
\text { General of } \\
\text { Treasury } \\
\text { (Setya \& } \\
\text { Wella, 2018). }\end{array}$ & $\begin{array}{l}\text { Melakukan } \\
\text { evaluasi tingkat } \\
\text { capability level } \\
\text { pada domain } \\
\text { EDM } 01 \text { dan } \\
\text { EDM } 02 \text { untuk } \\
\text { memastikan } \\
\text { sistem berjalan } \\
\text { dengan baik } \\
\text { dan } \\
\text { memberikan } \\
\text { manfaat bagi } \\
\text { user. }\end{array}$ & 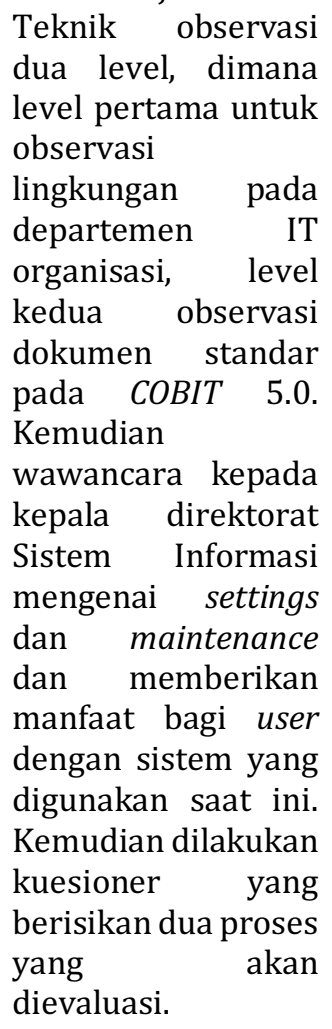 & $\begin{array}{l}\text { Sistem Informasi } \\
\text { pada Directorate } \\
\text { Generate of the } \\
\text { Treasury memiliki } \\
\text { hampir mencapai } \\
\text { level 5, karena } \\
\text { terdapat beberapa } \\
\text { hal yang } \\
\text { mengganggu } \\
\text { proses lainnya } \\
\text { dalam mencapai } \\
\text { tujuan organisasi }\end{array}$ & $\begin{array}{l}\text { International } \\
\text { Journal of New } \\
\text { Media } \\
\text { Technology, } \\
\text { Volume 1, } \\
\text { Nomor 1, 2018 }\end{array}$ \\
\hline 5 & $\begin{array}{l}\text { Evaluasi IT } \\
\text { Governance } \\
\text { Menggunaka } \\
\text { n COBIT } 5 \\
\text { (Studi Kasus: } \\
\text { PT. XYZ) } \\
\text { (Oktaviana et } \\
\text { al., 2019). }\end{array}$ & $\begin{array}{l}\text { Melakukan } \\
\text { evaluasi tata } \\
\text { Kelola } \\
\text { teknologi } \\
\text { informasi agar } \\
\text { dapat } \\
\text { mendapatkan } \\
\text { nilai capability } \\
\text { level di PT. XYZ }\end{array}$ & $\begin{array}{l}\text { Teknik } \\
\text { pengumpulan data } \\
\text { dimulai dengan } \\
\text { wawancara pada } \\
\text { beberapa } \\
\text { stakeholder, } \\
\text { kemudian observasi } \\
\text { pada sistem Citrix } \\
\text { Access Platform } \\
\text { System, kemudian } \\
\text { melakukan }\end{array}$ & $\begin{array}{l}\text { Hasil evaluasi pada } \\
\text { domain } \\
\text { APD04, } \\
\text { DPO02, } \\
\text { DSS01, MEA } 01 \\
\text { mendapatkan hasil } \\
\text { pada level } 3 .\end{array}$ & $\begin{array}{l}\text { Jurnal Pro } \\
\text { Bisnis, Volume } \\
\text { 12, Nomor 1, } \\
2019 \text {. }\end{array}$ \\
\hline
\end{tabular}




\begin{tabular}{|c|c|c|c|c|c|}
\hline No. & $\begin{array}{c}\text { Judul } \\
\text { Penelitian } \\
\text { dan Peneliti }\end{array}$ & $\begin{array}{c}\text { Tujuan } \\
\text { Peneltian }\end{array}$ & $\begin{array}{c}\text { Teknik } \\
\text { Pengumpulan Data }\end{array}$ & Hasil Penelitian & Publikasi \\
\hline 6 & $\begin{array}{l}\text { Audit Sistem } \\
\text { Informasi } \\
\text { Akademik } \\
\text { Menggunaka } \\
\text { n COBIT } 5 \text { di } \\
\text { Universitas } \\
\text { Jenderal } \\
\text { Achmad Yani } \\
\text { (Ekowansyah } \\
\text { et al., 2017) }\end{array}$ & $\begin{array}{l}\text { Tujuan } \\
\text { penelitian yang } \\
\text { dilakukan } \\
\text { adalah } \\
\text { mengukur dan } \\
\text { mengetahui } \\
\text { tingkat } \\
\text { kematangan } \\
\text { teknologi } \\
\text { informasi } \\
\text { akademik yang } \\
\text { diterapkan } \\
\text { Unjani } \\
\text { berdasarkan } \\
\text { data yang } \\
\text { diperoleh dari } \\
\text { sampel lingkungan } \\
\text { kampus Unjani }\end{array}$ & 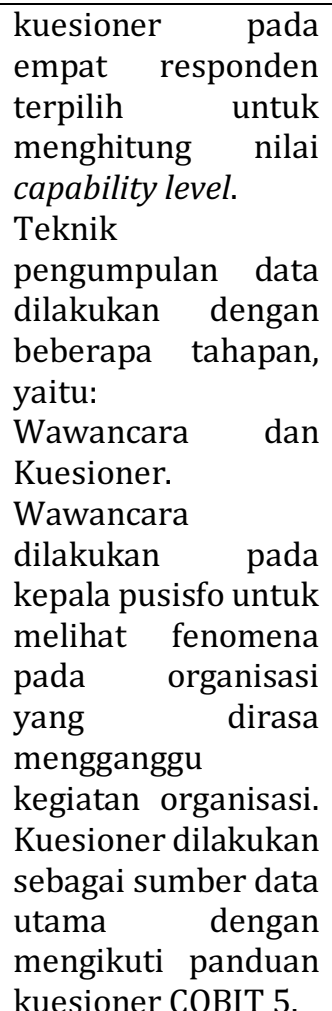 & $\begin{array}{l}\text { Hasil evaluasi pada } \\
31 \text { responden } \\
\text { dengan berfokus } \\
\text { pada domain EDM, } \\
\text { BAI, dan APO } \\
\text { memiliki hasil } \\
\text { akhir yaitu Sistem } \\
\text { Informasi } \\
\text { Akademik Unjani } \\
\text { memiliki tingkat } \\
\text { keseluruhan pada } \\
\text { level } 3 \text { atau } \\
\text { Established } \\
\text { Process, namun } \\
\text { perlu perbaikan } \\
\text { pada domain EDM } \\
\text { karena memiliki } \\
\text { nilai dibawah rata- } \\
\text { rata. }\end{array}$ & $\begin{array}{l}\text { Prosiding } \\
\text { Seminar } \\
\text { Nasional } \\
\text { Komputer dan } \\
\text { Informatika } \\
\text { (SENASKI) }\end{array}$ \\
\hline 7 & $\begin{array}{l}\text { Audit Sistem } \\
\text { Informasi } \\
\text { Menggunaka } \\
\text { n COBIT } 5 \\
\text { Domain DSS } \\
\text { Pada PT. } \\
\text { Erajaya } \\
\text { Swasembada. } \\
\text { Tbk (Wella, } \\
\text { 2016). }\end{array}$ & $\begin{array}{l}\text { Menciptakan IT } \\
\text { Governance } \\
\text { yang baik di } \\
\text { perusahaan, } \\
\text { untuk } \\
\text { mengetahui } \\
\text { bahwa } \\
\text { implementasi } \\
\text { TI sudah } \\
\text { dijalankan } \\
\text { dengan benar } \\
\text { dan di-deliver } \\
\text { secara optimal } \\
\text { berdasarkan IT } \\
\text { Strategic yang } \\
\text { telah dirancang } \\
\text { sebelumnya. }\end{array}$ & $\begin{array}{l}\text { Pada penelitian ini } \\
\text { penulis } \\
\text { menggunakan } \\
\text { teknik kuesioner } \\
\text { sebagai teknik } \\
\text { utama pengumpulan } \\
\text { data primer, dengan } \\
\text { populasi sebanyak } \\
30 \text { orang karyawan } \\
\text { perusahaan, serta } \\
\text { sampel sebanyak } 14 \\
\text { orang dari setiap } \\
\text { divisi perusahaan. } \\
\text { Selain menggunakan } \\
\text { kuesioner, penulis } \\
\text { juga menggunakan } \\
\text { teknik observasi } \\
\text { pada dokumen } \\
\text { pengoperasian } \\
\text { computer,lalu } \\
\text { Analisa prosedur } \\
\text { CAATs yang } \\
\text { dijalankan pada data } \\
\text { perusahaan. }\end{array}$ & $\begin{array}{l}\text { PT. Erahaya } \\
\text { Swasembada } \\
\text { berada tepat } \\
\text { diantara level } 3 \\
\text { atau Established } \\
\text { Process dan level } 4 . \\
\text { Sehingga sudah } \\
\text { mengimplementas } \\
\text { ikan pelayanan } \\
\text { dan dukungan } \\
\text { terhadap Tata } \\
\text { Kelola TI dengan } \\
\text { baik. Namun } \\
\text { diperlukan adanya } \\
\text { kontrol secara } \\
\text { berkelanjutan } \\
\text { terhadap proses TI } \\
\text { serta perlu adanya } \\
\text { self-assessment } \\
\text { yang teratur. }\end{array}$ & $\begin{array}{l}\text { ULTIMA } \\
\text { Information } \\
\text { System, } \\
\text { Volume } \\
\text { Nomor 1, } 2016 .\end{array}$ \\
\hline 8 & $\begin{array}{l}\text { Audit Sistem } \\
\text { Informasi } \\
\text { Universitas } \\
\text { Pendidikan } \\
\text { Ganesha } \\
\text { Dengan } \\
\text { Framework }\end{array}$ & $\begin{array}{l}\text { Penelitian ini } \\
\text { dilakukan } \\
\text { untuk } \\
\text { mengukur } \\
\text { kinerja dan } \\
\text { harapan } \\
\text { perusahaan }\end{array}$ & $\begin{array}{l}\text { Teknik } \\
\text { pengumpulan data } \\
\text { dilakukan dengan } \\
\text { menggunakan } \\
\text { kombinasi } \\
\text { observasi, }\end{array}$ & $\begin{array}{l}\text { Undiksha memiliki } \\
\text { nilai kapabilitas } \\
2,7 \text { dengan gap } \\
\text { sebesar } 1,3 \text { pada } \\
\text { level } 3 \text { atau, } \\
\text { dengan level yang } \\
\text { ditargetkan adalah }\end{array}$ & $\begin{array}{l}\text { Jurnal Sains } \\
\text { dan Teknologi, } \\
\text { Volume }\end{array}$ \\
\hline
\end{tabular}




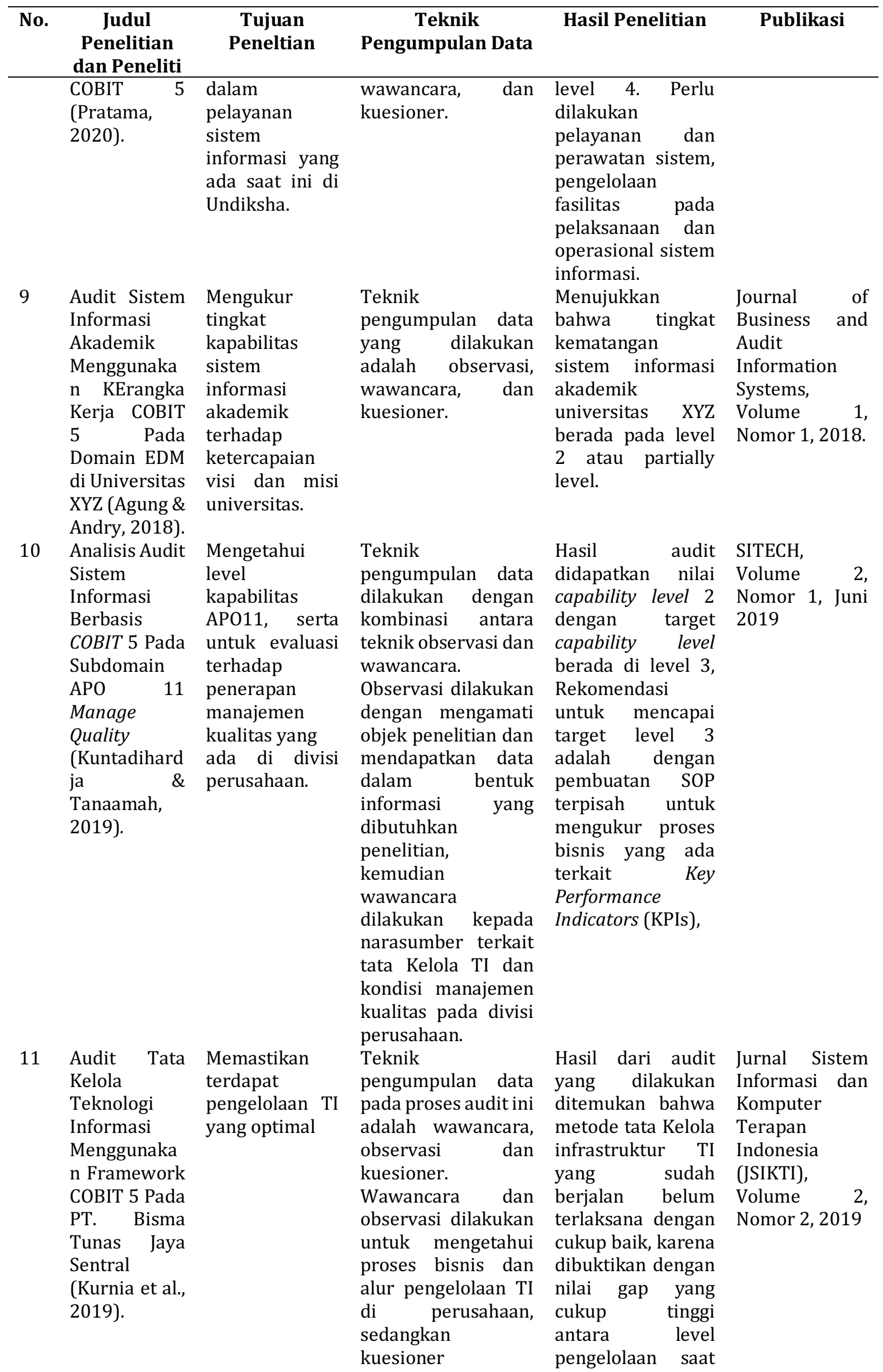




\begin{tabular}{|c|c|c|c|c|c|}
\hline No. & $\begin{array}{c}\text { Judul } \\
\text { Penelitian } \\
\text { dan Peneliti }\end{array}$ & $\begin{array}{c}\text { Tujuan } \\
\text { Peneltian }\end{array}$ & $\begin{array}{c}\text { Teknik } \\
\text { Pengumpulan Data }\end{array}$ & Hasil Penelitian & Publikasi \\
\hline 12 & $\begin{array}{l}\text { Audit Sistem } \\
\text { Informasi } \\
\text { Pada } \\
\text { Lampung } \\
\text { Post } \\
\text { Menggunaka } \\
\text { n Framework } \\
\text { COBIT } 5 \text { (Soni } \\
\text { et al., 2019). }\end{array}$ & $\begin{array}{l}\text { Memastikan } \\
\text { pengelolaan } \\
\text { keamanan } \\
\text { informasi TI } \\
\text { pada Lampung } \\
\text { Post. }\end{array}$ & 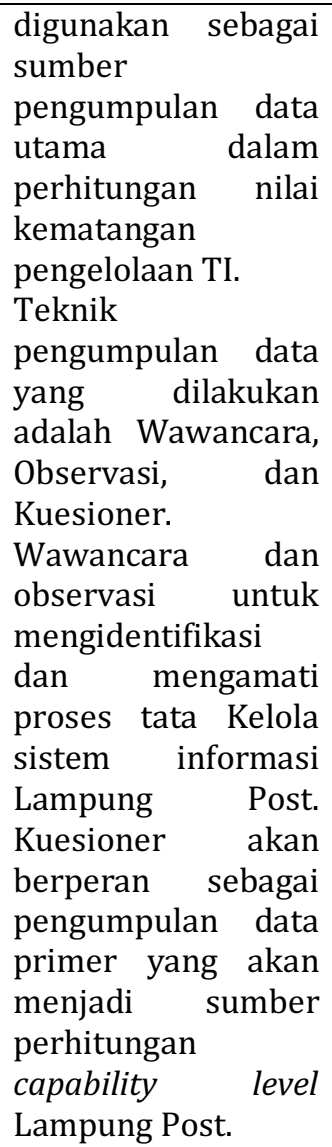 & $\begin{array}{lr}\text { Hasil dari } & \text { proses } \\
\text { audit } & \text { pada } \\
\text { Lampung } & \text { Post } \\
\text { menunjukkan hasil } \\
\text { bahwa nilai } \\
\text { current berada } \\
\text { pada skala tiga, } \\
\text { sedangkan nilai } \\
\text { yang diharapkan } \\
\text { adalah di level } \\
\text { lima, sehingga ada } \\
\text { gap yang cukup } \\
\text { tinggi. }\end{array}$ & $\begin{array}{l}\text { Jurnal } \\
\text { Informatika, } \\
\text { Volume 19, } \\
\text { Nomor 2, 2019 }\end{array}$ \\
\hline 13 & $\begin{array}{l}\text { Analysis- } \\
\text { Based } \\
\text { Information } \\
\text { Systems Audit } \\
\text { COBIT 5 In the } \\
\text { Domain } \\
\text { Deliver } \\
\text { Service and } \\
\text { Support (Case } \\
\text { Study: SIM-BL } \\
\text { in unit CDC } \\
\text { PT. Telkom } \\
\text { Centre. Tbk) } \\
\text { (Al-rasyid, } \\
\text { 2015). }\end{array}$ & $\begin{array}{l}\text { Untuk } \\
\text { mengevaluasi, } \\
\text { menilai } \\
\text { kapabilitas, } \\
\text { serta } \\
\text { Menyusun } \\
\text { rekomendasi } \\
\text { terhadap tata } \\
\text { Kelola TI yang } \\
\text { telah } \\
\text { diterapkan } \\
\text { informasi. }\end{array}$ & $\begin{array}{l}\text { Teknik } \\
\text { pengumpulan data } \\
\text { pada penelitian ini } \\
\text { adalah wawancara, } \\
\text { observasi, dan } \\
\text { kuesioner. } \\
\text { Wawancara dan } \\
\text { observasi dilakukan } \\
\text { untuk mengetahui } \\
\text { sasaran strategis } \\
\text { perusahaan dan } \\
\text { pemetaan } \\
\text { enterprise, } \\
\text { kemudian dilakukan } \\
\text { penyebaran } \\
\text { kuesioner dalam } \\
\text { rangka penentuan } \\
\text { nilai capability level, } \\
\text { gap level, dan gap } \\
\text { analysis. }\end{array}$ & 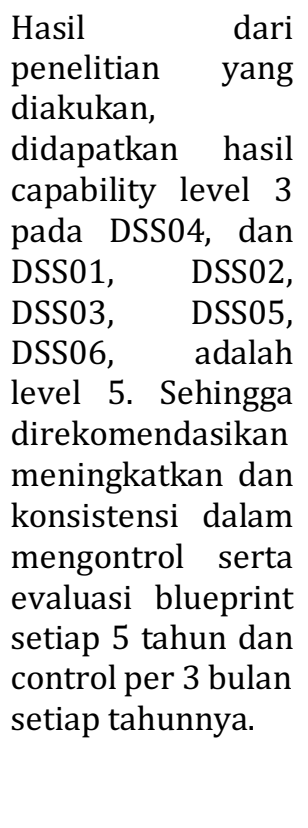 & $\begin{array}{l}\text { e-Proceeding of } \\
\text { Engineering: } \\
\text { Volume 2, } \\
\text { Nomor 2, 2015 }\end{array}$ \\
\hline 14 & $\begin{array}{l}\text { Audit Sistem } \\
\text { Informasi } \\
\text { Akademik } \\
\text { Menggunaka } \\
\mathrm{n} \text { COBIT } 5 \\
\text { Pada SMK } \\
\text { SEHATI } \\
\text { KARAWANG }\end{array}$ & $\begin{array}{l}\text { Membuat } \\
\text { perencanaan } \\
\text { audit sistem } \\
\text { informasi } \\
\text { akademik yang } \\
\text { menghasilkan } \\
\text { dokumen } \\
\text { terkait tingkat }\end{array}$ & $\begin{array}{l}\text { Teknik } \\
\text { pengumpulan data } \\
\text { yang dilakukan } \\
\text { adalah observasi, } \\
\text { wawancara, dan } \\
\text { perancangan } \\
\text { kuesioner. } \\
\text { Observasi dilakukan }\end{array}$ & $\begin{array}{l}\text { Hasil audit pada } \\
\text { domain DSS } \\
\text { ditemukan bahwa } \\
\text { masih berada pada } \\
\text { capability level 1, } \\
\text { sehingga perlu } \\
\text { adanya } \\
\text { kelengkapan }\end{array}$ & $\begin{array}{l}\text { Conference on } \\
\text { Innovation and } \\
\text { Application of } \\
\text { Science and } \\
\text { Technology } \\
\text { (CIASTECH } \\
2020 \text { ) }\end{array}$ \\
\hline
\end{tabular}




\begin{tabular}{|c|c|c|c|c|c|}
\hline No. & $\begin{array}{c}\text { Judul } \\
\text { Penelitian } \\
\text { dan Peneliti }\end{array}$ & $\begin{array}{l}\text { Tujuan } \\
\text { Peneltian }\end{array}$ & $\begin{array}{c}\text { Teknik } \\
\text { Pengumpulan Data }\end{array}$ & Hasil Penelitian & Publikasi \\
\hline 15 & $\begin{array}{l}\text { Audit Sistem } \\
\text { Informasi } \\
\text { Absensi Pada } \\
\text { Kejaksaan } \\
\text { Negeri Kota } \\
\text { Bandung } \\
\text { Menggunaka } \\
\text { n Framework } \\
\text { COBIT } \\
\text { (Rabhani et } \\
\text { al., 2020). }\end{array}$ & \begin{tabular}{l}
\multicolumn{2}{l}{ engevaluasi } \\
tata kelola \\
informasi yang \\
berjalan \\
Kejaksaan \\
Negeri \\
Bandung
\end{tabular} & 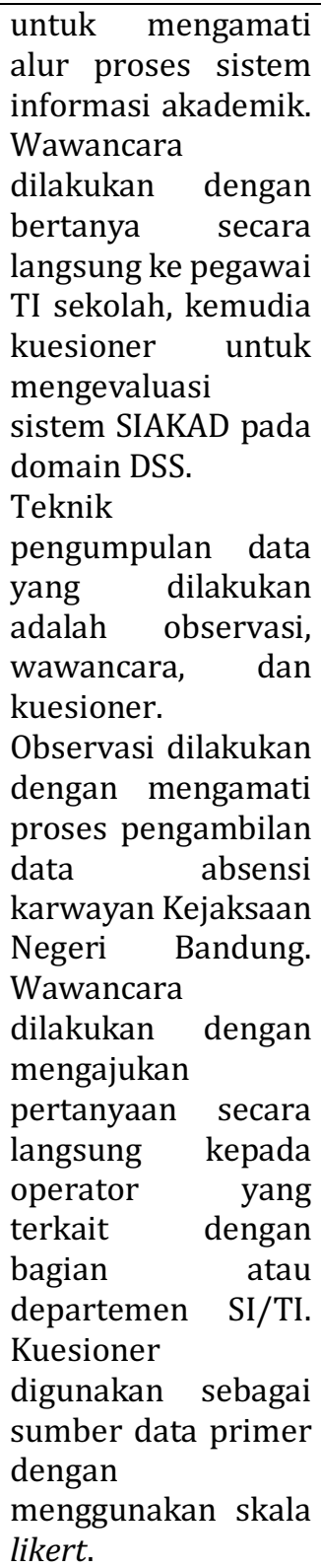 & $\begin{array}{l}\text { Berdasarkan hasil } \\
\text { perhitungan } \\
\text { kuesioner } \\
\text { didapatkan hasil } \\
\text { dari para } \\
\text { responden untuk } \\
\text { capability level 2,4 } \\
\text { pada rentangan } 1 \\
\text { hingga } 4 \text {. Sehingga } \\
\text { keseluruhan } \\
\text { proses } \\
\text { pengelolaan } \\
\text { telah diketahui } \\
\text { oleh instansi, } \\
\text { namun Kejaksaan } \\
\text { masih perlu } \\
\text { melakukan } \\
\text { perbaikan pada } \\
\text { proses di domain } \\
\text { MEA. }\end{array}$ & $\begin{array}{l}\text { Jurnal } \\
\text { SISFOKOM } \\
\text { (Sistem } \\
\text { informasi dan } \\
\text { computer) } \\
\text { Volume } \\
\text { Nomor 2 }\end{array}$ \\
\hline
\end{tabular}

\section{Pembahasan Matriks Sintetis}

Berdasarkan best practice audit sistem informasi (IT Governance Institute, 2004) dan ISO 27002 tahapan audit sistem informasi secara umum dibagi menjadi 3 tahapan: Perencanaan dan Persiapan, Pelaksanaan Audit, dan Pelaporan Hasil Audit. 


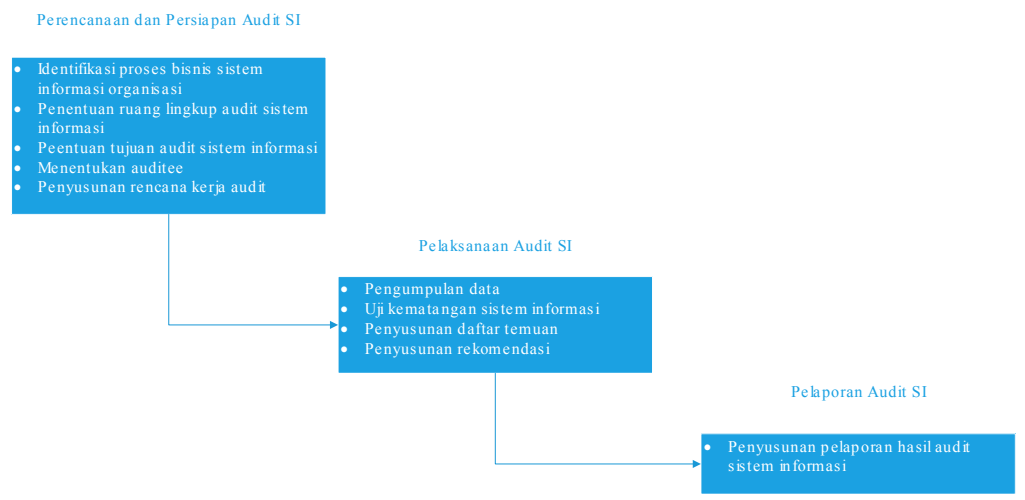

Gambar 2. Tahapan pelaksanaan audit sistem informasi

Pada tahapan perencanaan dan persiapan merupakan tahapan awal dilakukannya proses audit, hasil dari tahapan ini akan menghasilkan pengetahuan bagi auditor mengenai proses bisnis dan TI organisasi, ruang lingkup dan tujuan yang telah ditentukan, serta pendekatan audit yang akan dilakukan. Berdasarkan tabel matriks sintesis terdapat beberapa pendekatan yang dapat dilakukan dalam melakukan audit sistem informasi, yakni:

Tabel 2. Jenis pendekatan audit sistem informasi

\begin{tabular}{|c|c|c|c|}
\hline $\begin{array}{c}\text { Jenis } \\
\text { Pendekatan }\end{array}$ & Deskripsi & Keunggulan & Kelemahan \\
\hline $\begin{array}{l}\text { Audit } \\
\text { Around the } \\
\text { Computer }\end{array}$ & $\begin{array}{l}\text { Pendekatan ini dilakukan } \\
\text { apabila dokumen sumber } \\
\text { sudah ada dalam bentuk } \\
\text { kertas sehingga secara visual } \\
\text { dapat dilihat. Pada } \\
\text { pendekatan ini dokumen- } \\
\text { dokumen organisasi dapat } \\
\text { dengan mudah ditemukan, } \\
\text { pendekatan audit ini cukup } \\
\text { dilakukan terhadap aspek } \\
\text { input dan output sistem } \\
\text { aplikasi saja. }\end{array}$ & 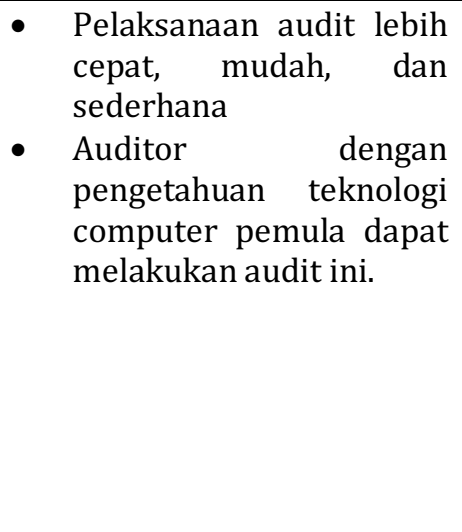 & $\begin{array}{l}\text { Jika terjadi } \\
\text { perubahan di } \\
\text { dalam lingkungan } \\
\text { organisasi yang } \\
\text { menyebabkan } \\
\text { mungkin terjadi } \\
\text { adanya perubahan } \\
\text { sistem, maka } \\
\text { auditor tidak } \\
\text { dapat menilai } \\
\text { apakah sistem } \\
\text { berjalan dengan } \\
\text { baik atau tidak. }\end{array}$ \\
\hline $\begin{array}{l}\text { Audit } \\
\text { Through } \\
\text { Computer }\end{array}$ & $\begin{array}{l}\text { Pendekatan ini dilakukan } \\
\text { dengan melakukan proses } \\
\text { input yang cukup besar dan } \\
\text { output yang cukup besar } \\
\text { (cukup kompleks), sehingga } \\
\text { audit dilakukan dengan } \\
\text { menelaah validitas input dan } \\
\text { output sistem secara } \\
\text { komprehensif. } \\
\text { pendekatan ini auditor } \\
\text { mengunakan bantuan tools }\end{array}$ & $\begin{array}{l}\text { Dapat mendapatkan } \\
\text { informasi menyeluruh } \\
\text { mengenai spesifikasi dan } \\
\text { kemampuan dari sistem } \\
\text { yang di audit }\end{array}$ & $\begin{array}{l}\text { Diakrenakan } \\
\text { memerluka audit } \\
\text { spesifikasi yang } \\
\text { menyeluruh, maka } \\
\text { diperlukan waktu } \\
\text { dan biaya yang } \\
\text { cukup tinggi agar } \\
\text { dapat } \\
\text { menghasilkan hasi } \\
\text { audit yang } \\
\text { maksimal }\end{array}$ \\
\hline
\end{tabular}




\begin{tabular}{|c|c|c|c|}
\hline $\begin{array}{c}\text { Jenis } \\
\text { Pendekatan }\end{array}$ & Deskripsi & Keunggulan & Kelemahan \\
\hline $\begin{array}{l}\text { Audit with } \\
\text { The } \\
\text { Computer }\end{array}$ & $\begin{array}{l}\text { Pada pendekatan ini auditor } \\
\text { memanfaatkan computer } \\
\text { secara menyeluruh sebagai } \\
\text { alat bantu audit, seperti } \\
\text { general audit software (ACL, } \\
\text { IDEA) ataupun software } \\
\text { pendukung lain seperti } \\
\text { (Microsoft Excel, Google } \\
\text { Sheets). Penggunaan alat } \\
\text { bantu ini bertujuan untuk } \\
\text { mengotomatisasi prosedur } \\
\text { pelaksanaan audit secara } \\
\text { menyeluruh. Pendekatan } \\
\text { audit ini dilakukan untuk } \\
\text { melakukan evaluasi } \\
\text { kehandalan data, file, } \\
\text { ataupun record organisasi } \\
\text { dengan jenis organisasi yang } \\
\text { menerapkan IT cukup } \\
\text { kompleks. }\end{array}$ & 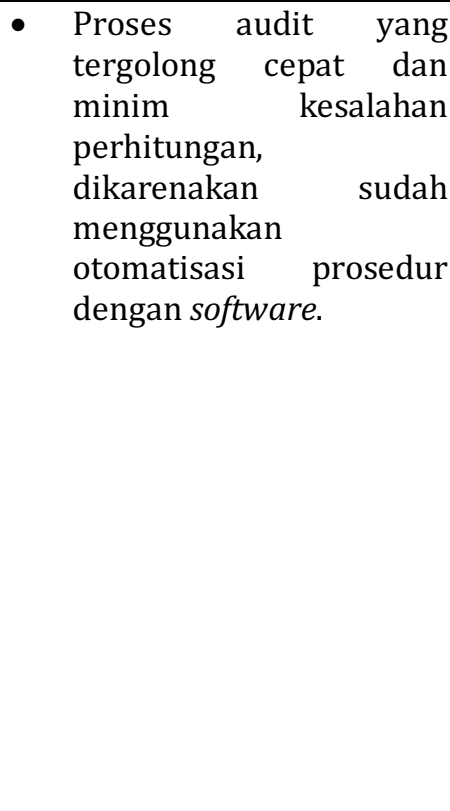 & $\begin{array}{l}\text { Memerlukan } \\
\text { kemampuan } \\
\text { computer yang } \\
\text { cukup tinggi bagi } \\
\text { auditor, terutama } \\
\text { dalam memahami } \\
\text { jenis-jenis sistem } \\
\text { organisasi, serta } \\
\text { pemahaman } \\
\text { terhadap } \\
\text { yang tools } \\
\text { digunakan. }\end{array}$ \\
\hline
\end{tabular}

Flowchart penentuan pendekatan audit yang didasarkan pada ruang lingkup audit dapat dilihat sebagai berikut:

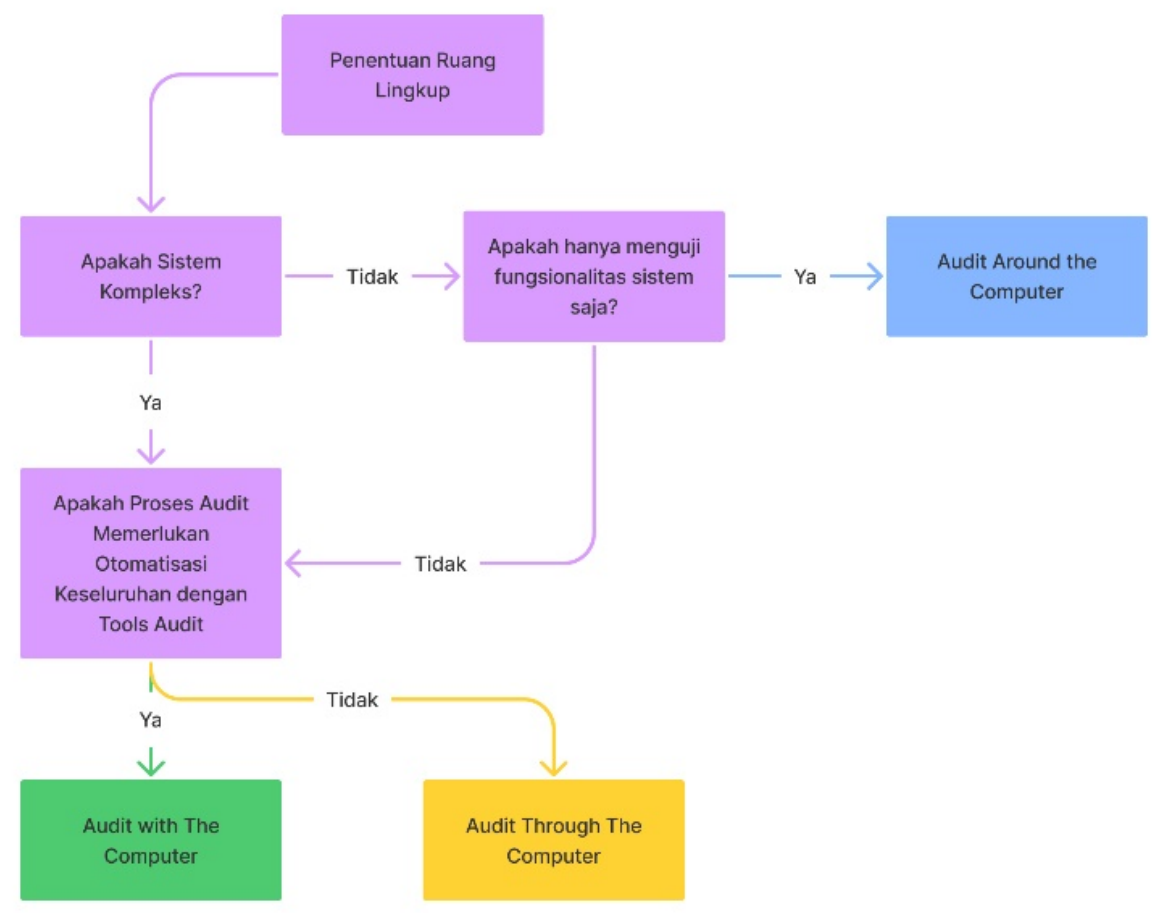

Gambar 3. Alur penentuan pendekatan audit sistem informasi

Pada tahapan pelaksanaan audit sistem informasi dilakukan untuk menguji kepatutan dan kesesuaian sistem informasi organisasi. Salah satu fase terpenting dalam tahapan ini adalah fase pengumpulan data atau evidence phase, menurut (Andry \& Setiawan, 2019) dan (Arisanti, 2011), jika tingkat pemakaian IT tinggi maka disarankan menggunakan pendekatan audit with computer dengan bantuan Computer Aided Auditing Technique (CAAT). Teknik pengambilan data pada COBIT 5 sesuai prosedur yang ditetapkan adalah: 
a. Wawancara, pada teknik pengumpulan data wawancara diawali dengan pembuatan form pertanyaan yang akan diajukan saat proses pengumpulan data, sehingga saat audit dilakukan auditor sudah memiliki daftar pertanyaan yang akan diajukan kepada narasumber. Hasil dari proses wawancara akan menghasilkan dokumen fakta dan bukti, pemetaan proses bisnis organisasi, RACI Chart, ataupun struktur organisasi.

b. Survei, pada teknik pengumpulan data survey, diawali dengan penyusunan daftar pertanyaan yang akan diajukan ke masing-masing responden, penentuan responden didapatkan dari hasil wawancara dan observasi auditor, hasil survey akan menjadi data primer dalam penentuan nilai maturity level.

c. Peninjauan terhadap dokumen, dilakukan untuk mengumpulkan informasi terkait pemetaan keseluruhan sistem yang ada di organisasi, bertujuan untuk meninjau aktivitas penggunaan sistem informasi di organisasi.

d. Observasi, merupakan teknik yang bertujuan untuk memeriksa dan memastikan dokumen data fakta dan bukti dari tahapan wawancara dikonfirmasi oleh narasumber. Pada tahapan observasi dapat dilakukan secara compliance test maupun substantive test.

- Compliance test atau uji kepatutan merupakan uji kepatutan sistem informasi terhadap prosedur yang dijadikan acuan dalam pelaksanaan audit.

- Substantive test merupakan uji terhadap aplikasi dan infrastruktur yang mendukung pelaksanaan sistem informasi organisasi, sehingga menekankan pada pengujian integritas proses yang berlangsung.

e. Informasi Brainstorming Group Session, merupakan teknik untuk menentukan penugasan, deskripsi tugas dari masing-masing auditor jika audit dilakukan secara bertim.

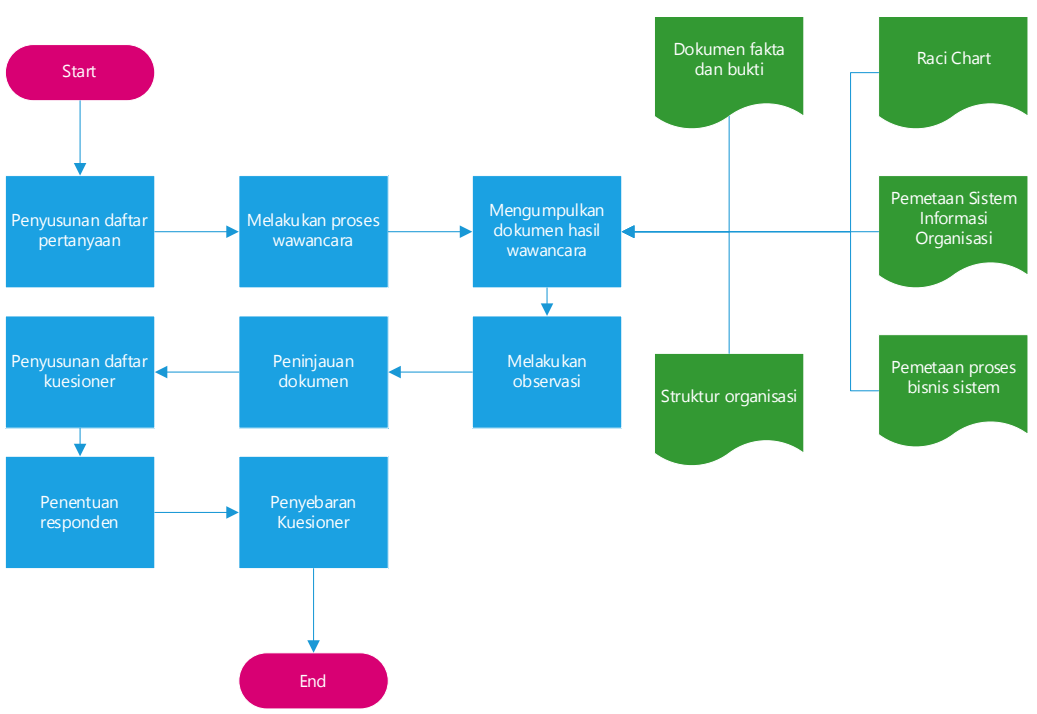

Gambar 4. Alur proses pengumpulan data framework COBIT

Penentuan teknik pengambilan data yang akan digunakan auditor dapat mengacu pada hasil dari fase pertama yakni penentuan ruang lingkup audit sistem informasi, semakin tinggi ruang lingkup sistem informasi organisasi maka diperlukan variasi teknik pengambilan data yang cukup agar hasil analisi audit sistem informasi dapat mendapatkan hasil yang maksimal dan relevan dengan kondisi organisasi.

\section{SIMPULAN DAN SARAN}

Pengumpulan data merupakan aspek fundamental dalam pelaksanaan audit sistem informasi, kualitas data yang didapatkan akan mempengaruhi tingkat akurasi audit sistem informasi yang dilaksanakan. Kesalahan dalam penggunaan metode pengumpulan data akan dapat hasil audit yang kurang relevan dan kurang akurat dengan kondisi organisasi yang diaudit. Tahapan audit sistem informasi secara umum dibagi menjadi 3 tahapan: Perencanaan dan Persiapan, Pelaksanaan Audit, dan Pelaporan Hasil Audit. Sebelum memulai pelaksanaan audit di bagian pengumpulan data, ada baiknya auditor menentukan pendekatan audit yang akan dilakukan, pendekatan audit dibagi menjadi tiga, yakni: Audit Through 
Computer, Audit Around the Computer, Audit with The Computer. Teknik pengumpulan data pada audit sistem informasi dengan framework cobit diantaranya: wawancara, observasi, studi dokumen, survey, dan. Penentuan teknik pengambilan data dapat mengacu pada tahapan pertama audit yakni penentuan ruang lingkup audit, hal ini sangat penting mengingat pengumpulan data akan mempengaruhi seluruh tahap lanjutan dari audit sistem informasi, termasuk mempengaruhi hasil audit.

\section{Ucapan Terima Kasih}

Penulis menyadari sangat sulit menyelesaikan penelitian ini tanpa bantuan dan bimbingan serta kesabaran dari berbagai pihak. Untuk itu, penulis mengucapkan terimakasih kepada: Bapak I Made Ardwi Pradnyana, S.T., M.T. dan bapak I Gusti Lanang Agung Raditra Putra, S.T., M.T. selaku dosen pembimbing yang telah membimbing penulis menyelesaikan penelitian ini dengan sabar dan memberikan banyak masukan positif.

\section{Daftar Pustaka}

Agung, H., \& Andry, J. F. (2018). Audit Sistem Informasi Akademik Menggunakan Kerangka Kerja COBIT 5 pada Domain EDM pada Universitas XYZ. JBASE - Journal of Business and Audit Information Systems, 1(1), 40-51. https://doi.org/10.30813/.v1i1.1143

Al-rasyid, A. (2015). Analisis Audit Sistem Informasi Berbasis COBIT 5 Pada Domain Deliver , Service , and Support ( DSS ) ( Studi Kasus: SIM-BL di Unit CDC PT Telkom Pusat. Tbk ). E-Proceeding of Engineering, $2(2)$, 6110-6123. https://openlibrary.telkomuniversity.ac.id/pustaka/files/101873/bab1/analisis-audit-sisteminformasi-berbasis-cobit-5-pada-domain-deliver-service-and-support-dss-studi-kasus-sim-bl-diunit-cdc-pt-telkom-pusat-tbk-.pdf

Amalia, M. N., Akbar, F., Risdiani, I., Islaha, A., \& Srilena, N. (2020). Audit Sistem Informasi pada Perpustakaan ARS University Menggunakan Framework COBIT 5. Jurnal Sains Dan Informatika, 6(2), 139-147. https://doi.org/10.34128/jsi.v6i2.226

Andry, J. F., \& Hartono, H. (2017). Performance Measurement of IT Based on COBIT Assessment : A Case Study. Jurnal Sistem Informasi Indonesoa (USII), 2(2017), 1-13. http://publications.aisindo.org/index.php/JSII/article/view/66

Andry, J. F., \& Setiawan, A. K. (2019). It Governance Evaluation Using Cobit 5 Framework on the National Library. Jurnal Sistem Informasi, 15(1), 10-17. https://doi.org/10.21609/jsi.v15i1.790

Arens, A. A., Elder, R. J., \& Beasley, M. S. (2017). Auditing and Assurance Services An Integrated Approach.

Arisanti, D. (2011). AUDIT SISTEM INFORMASI DITINJAU DARI PERSPEKTIF KEUANGAN MENGGUNAKAN STANDAR COBIT 4.1 PADA DIREKTORAT KEUANGAN PELABUHAN INDONESIA III (Vol. 1).

Bayastura, S. F., Krisdina, S., \& Widodo, A. P. (2021). Analisis Dan Perancangan Tata Kelola Teknologi Informasi Menggunakan Framework Cobit 2019 Pada Pt . Xyz Analysis and Design of Information Technology Governance Using the Cobit 2019 At Pt. Xyz. 4(1), 68-75. https://doi.org/10.33387/jiko

Ekowansyah, E., H, C. Y., Puspita, \& Sabrina, N. (2017). Audit Sistem Informasi Akademik Menggunakan COBIT 5 di Universitas Jenderal Achmad Yani. Prosiding Seminar Nasional Komputer Dan Informatika (Senaski) 2017 (ISBN: $978 \quad-602 \quad-60250 \quad-\quad 1 \quad-2), \quad 2017, \quad 201-206$. https://doi.org/10.1371/journal.pone.0197468

Ishaq, A., Mukhtar, M., Wahyudi, M., \& Indriani, K. (2017). Information technology governance using cobit 4.0 domain delivery support and monitoring evaluation. Journal of Theoretical and Applied Information Technology, 95(20), 5304-5315.

IT Governance Institute. (2004). COBIT Student Book. In Governance An International Journal Of Policy And Administration.

Kuntadihardja, C. H., \& Tanaamah, A. R. (2019). Analisis Audit Sistem Informasi Berbasis COBIT 5 Pada Subdomain AP011 Manage Quality. Jurnal SITECH : Sistem Informasi Dan Teknologi, 2(1), 109-120. https://doi.org/10.24176/sitech.v2i1.3492

Kurnia, H. M., Shofa, R. N., \& Rianto, R. (2019). Audit Tata Kelola Teknologi Informasi Menggunakan Framework COBIT 5 Berdasarkan Domain AP012. Jurnal SITECH : Sistem Informasi Dan Teknologi, 1(2), 99-106. https://doi.org/10.24176/sitech.v1i2.2723

Mirzaqon, A. T., \& Purwoko, B. (2017). Studi Kepustakaan Mengenai Landasan Teori Dan Praktik Konseling Expressive Writing Library. Jurnal BK UNESA, 4(1), 1-8.

Nainggolan, J. (2021). Analisis Perbandingan Framework COBIT 5 . 0 Dengan ITIL Dalam Mengaudit Sistem Informasi. 5, 76-85.

Oktaviana, L. D., Pribadi, P., \& Sabrinawati, M. (2019). Evaluasi IT Governance Menggunakan Framework COBIT 5 ( Studi Kasus : PT . XYZ ). Jurnal Pro Bisnis, 12(1), 56-68. 
Pratama, P. A. (2020). AUDIT SISTEM INFORMASI UNIVERSITAS PENDIDIKAN GANESHA dengan FRAMEWORK COBIT 5. JST (Jurnal Sains Dan Teknologi), 9(2). https://doi.org/10.23887/jstundiksha.v9i2.25948

Rabhani, A. P., Maharani, A., Putrie, A. A., Anggraeni, D., Azisabil, H. F., Cantika, I., Cahyani, I., Destianti, L. L., Mahmud, P. T., \& Firmansyah, R. (2020). Audit Sistem Informasi Absensi Pada Kejaksaan Negeri Kota Bandung Menggunakan Framework Cobit 5. Jurnal Sisfokom (Sistem Informasi Dan Komputer), 9(2), 275-280. https://doi.org/10.32736/sisfokom.v9i2.890

Rahayu, S. R. (2018). Studi Literatur: Peranan Bahasa Inggris Untuk Tujuan Bisnis Dan Pemasaran. 1(4), 149.

Rahayu, T., Matondang, N., \& Hananto, B. (2020). Audit Sistem Informasi Akademik Menggunakan Metode Cobit 5. Jurnal Teknologi Informasi Dan Pendidikan, 13(1), 117-123. https://doi.org/10.24036/tip.v13i1.305

Sari, M., \& Asmendri. (2018). Penelitian Kepustakaan (Library Research) dalam Penelitian Pendidikan IPA. Penelitian Kepustakaan (Library Research) Dalam Penelitian Pendidikan IPA, 2(1), 15. https://ejournal.uinib.ac.id/jurnal/index.php/naturalscience/article/view/1555/1159

Setya, D. U., \& Wella, W. (2018). COBIT 5.0: Capability Level of Information Technology Directorate General of Treasury. International Journal of New Media Technology, 5(1), 18-24. https://doi.org/10.31937/ijnmt.v5i1.614

Soni, S., Wijaya, H., \& Aziz, R. Z. A. (2019). Audit Sistem Informasi Menggunakan Metode Framework Cobit 5. Jurnal Informatika, 19(2), 116-126.

Sukmajaya, I. B., \& Johanes Fernandes Andry. (2017). Audit Sistem Informasi Pada Aplikasi Accurate Menggunakan Model Cobit Framework 4.1 (Studi Kasus: PT. Setia Jaya Teknologi). Seminar Nasional Teknoka, 2(2502-8782), 42-51.

Supriyadi, S. (2017). Community of Practitioners: Solusi Alternatif Berbagi Pengetahuan antar Pustakawan. Lentera Pustaka: Jurnal Kajian Ilmu Perpustakaan, Informasi Dan Kearsipan, 2(2), 83. https://doi.org/10.14710/lenpust.v2i2.13476

Ulhaq, Z. S., \& Rahmayanti, M. (2020). Panduan Penulisan Skripsi Literatur Review. In Universitas Islam negeri Maulana Malik Ibrahim Malang (Vol. 1, Issue 1).

Wella. (2016). Audit Sistem Informasi Menggunakan Cobit 5 . 0 Domain DSS pada. ULTIMS InfoSys, VII(1), 38-44.

Yaniar, S. R., Nur, A. F., \& Wahyudi, R. (2020). IS Governance Evaluation Using COBIT 5 Framework on the Central Statistics Agency of Banyumas District. Journal of Computer Science and Engineering (JCSE), 1(1), 1-9. https://doi.org/10.36596/jcse.v1i1.9 